\title{
Early Detection of Anthracycline Cardiotoxicity in a Rabbit Model: Left Ventricle Filling Pattern versus Troponin T Determination
}

\author{
M. ŠTĚRBA ${ }^{1}$, T. ŠIMŮNEK ${ }^{2}$, O. POPELOVÁ ${ }^{1}$, A. POTÁČOVÁ ${ }^{3}$ \\ M. ADAMCOVÁ ${ }^{3}$, Y. MAZUROVÁ ${ }^{4}$, M. HOLEČKOVÁ ${ }^{5}$, V. GERŠL ${ }^{1}$
}

${ }^{1}$ Department of Pharmacology, ${ }^{3}$ Department of Physiology, ${ }^{4}$ Department of Histology and Embryology, Faculty of Medicine in Hradec Králové, ${ }^{2}$ Department of Biochemical Sciences, Faculty of Pharmacy in Hradec Králové, Charles University in Prague and ${ }^{5}$ Department of Clinical Biochemistry and Diagnostics, University Teaching Hospital in Hradec Králové, Czech Republic

Received May 16, 2006

Accepted September 1, 2006

On-line available December 19, 2006

\begin{abstract}
Summary
Anthracycline cardiotoxicity represents a serious risk of anticancer chemotherapy. The aim of the present pilot study was to compare the potential of both the left ventricular (LV) filling pattern evaluation and cardiac troponin $\mathrm{T}$ (cTnT) plasma levels determination for the early detection of daunorubicin-induced cardiotoxicity in rabbits. The echocardiographic measurements of transmitral LV inflow as well as cTnT determinations were performed weekly for 10 weeks in daunorubicin ( $3 \mathrm{mg} / \mathrm{kg}$ weekly) and control groups ( $\mathrm{n}=5$, each). Surprisingly, no significant changes in LVfilling pattern were observed through the study, most likely due to the xylazine-containing anesthesia, necessary for appropriate resolving of the $\mathrm{E}$ and $\mathrm{A}$ waves. In contrast to the echographic measurement, the $\mathrm{dP} / \mathrm{dt}_{\min }$ index obtained invasively at the end of the study revealed a significant impairment in LV relaxation, which was further supported by observed disturbances in myocardial collagen content and calcium homeostasis. However, at the same time cTnT plasma levels were progressively rising in the daunorubicin-treated animals from the $5^{\text {th }}$ week $(0.024 \pm 0.008 \mu \mathrm{g} / \mathrm{l})$ until the end of the experiment $(0.186 \pm 0.055 \mu \mathrm{g} / \mathrm{l})$. Therefore, in contrast to complicated non-invasive evaluation of diastolic function, cTnT is shown to be an early and sensitive marker of anthracycline-induced cardiotoxicity in the rabbit model.
\end{abstract}

Key words

Daunorubicin $\bullet$ Anthracyclines $\bullet$ Cardiotoxicity $\bullet$ Early detection $\bullet$ Diastolic dysfunction $\bullet$ Cardiac troponin T

\section{Introduction}

Anthracycline antibiotics (e.g. doxorubicin, daunorubicin, epirubicin) belong to the most effective chemotherapeutic agents in the treatment of both hematological and solid malignancies (Yee 2005, Chabner et al. 2006). Cardiotoxicity, however, represents a serious adverse reaction that largely limits their therapeutic potential and threatens the cardiac function of cancer survivors. All anthracycline derivatives may 
induce cardiac damage that can result even in lifethreatening complication of chemotherapy. The main risk is associated with their chronic administration, when severe cardiomyopathy and heart failure may develop later or any time after completion of the treatment (von Hoff et al. 1979, Hrdina et al. 2000, Gharib and Burnett 2002, Minotti et al. 2004).

As the anthracycline-induced cardiotoxicity is largely irreversible, it is crucial to detect the myocardial injury at its earliest possible stage. Among the first approaches employed for sensitive and reliable detection of anthracycline cardiotoxicity was an endocardial biopsy. However, its invasive nature hinders and in fact nearly prevents its routine use in seriously sick oncologic patients. Actual recommendations for cardiac monitoring of anthracycline-treated patients are mostly based on the non-invasive examination of the left ventricular (LV) systolic function, since its decline is a well-known hallmark of anthracycline cardiotoxicity (Alexander $e t$ al. 1979, Shan et al. 1996, Tjeerdsma et al. 1999, Elbl et al. 2003, 2005). Both echocardiography and radioventriculography are employed, but a relatively low sensitivity of these approaches does not allow to cover the early phases of myocardial injury so that only more pronounced and distinct cardiotoxicity can be revealed (Shan et al. 1996, Tjeerdsma et al. 1999, Suter and Meier 2002).

While the effect of anthracyclines on the systolic function and its prognostic value is well established, the status of diastolic function, which actually may precede the impairment in contractility, remains to be clarified. As the diastolic function can be estimated non-invasively by Doppler echocardiography, its serial evaluation is well feasible. Several clinical studies dealing with the assessment of the diastolic function in anthracyclinetreated patients were carried out and resulted in rather variable and in some cases also contradictory outcomes (Marchandise et al. 1989, Ewer et al. 1994, Bu'Lock et al. 1999, Bossi et al. 2001, Clements et al. 2002, Nousiainen et al. 2002, Elbl et al. 2003, Nakamae et al. 2004). However, these findings could potentially be affected by heterogeneity of patients (e.g. with respect to age, sex and anamnesis), dosage scheme, combination of chemotherapeutics, presence of chest irradiation, and the liquid load enhancing the excretion of metabolites. Interestingly, to our knowledge, there are no available data on the time-course of changes of the diastolic function in time obtained from a validated and wellreproducible experimental model of anthracyclineinduced cardiomyopathy.
Apart from the examination of cardiac function, the modern advances in monitoring of chemotherapyinduced cardiotoxicity have brought the selective biochemical markers of cardiac injury into focus. This approach theoretically might be of special value for the detection of early cardiotoxicity, since a low-level release of myocardial biomolecules might be detected using sensitive analytical methods before any impairment of the heart function occurs (Petricoin et al. 2004). To date, probably the most interesting results have been described with cardiac troponins (Specchia et al. 2005, Adamcová et al. 2005, Lipshultz et al. 1997, 2004, Herman et al. 1998), although other biochemical markers, e.g. natriuretic peptides, are also studied (Horáček et al. 2005, Koh et al. 2004). While both cardiac troponin $\mathrm{T}$ and I are at present firmly settled as biomarkers in the diagnosis of myocardial infarction, their potential role in the early diagnosis of chemotherapy-induced cardiotoxicity and particularly in its early stages is not yet completely understood.

Several clinical as well as experimental studies have reported a rise of cardiac troponins during or after the anthracycline treatment (Herman et al. 1998, Adamcová et al. 2005). Moreover, some authors suggest that even subtle early elevations of cardiac troponins in plasma of anthracycline treated patients might predict an occurrence of chronic or delayed cardiotoxicity (Cardinale et al. 2004). However, the exact value of elevated cardiac troponins for diagnosis and reliable prediction of chronic or late anthracycline cardiotoxicity is not yet well established and it deserves further studies. So far, most studies have used only few different selected time points for troponin $\mathrm{T}$ determination, which offer only limited information and do not allow to fully understand the role of troponin $\mathrm{T}$ as a biomarker during the whole anthracycline treatment. To date, there is a lack of a systematic longitudinal study examining troponin $\mathrm{T}$ levels before and periodically throughout the period of the development of chronic anthracycline cardiotoxicity.

The aim of the present pilot study was therefore to explore and compare the potential of both the LVfilling pattern evaluation and plasma troponin $\mathrm{T}$ determination for an early detection of daunorubicininduced cardiotoxicity in rabbits.

\section{Methods}

\section{Experimental animals}

Fifteen Chinchilla male rabbits (3.5-4.5 $\mathrm{kg}$ at the 
beginning of the study) were used in this study. They were housed under a $12 \mathrm{~h}$ light cycle, constant temperature and humidity. The animals had free access to water and a standard laboratory pellet diet. The animal experiments were performed in accordance with the "Guide for the Care and Use of Laboratory Animals" (1996) and under the supervision of the Ethical Committee of the Medical Faculty in Hradec Králové.

\section{Experimental design}

In this study both the LV-filling pattern and plasma levels of troponin $\mathrm{T}$ were examined weekly in the daunorubicin and control groups $(n=5$, each) during 10 weeks. For appropriate evaluation of all parameters of the LV-filling the combined anesthetic regimen (ketamine + xylazine) used by others for this purpose (Rungwerth et al. 2004, Nagueh et al. 2000, Litwin et al. 1994) had to be employed. However, since xylazine itself may have certain hemodynamic effects, another group of animals examined under ketamine alone (the ketamine group, $n=5$ ) was introduced to the study. The daunorubicin group was injected with daunorubicin ( $3 \mathrm{mg} / \mathrm{kg}$, once weekly for 10 weeks) in a validated schedule for induction of daunorubicin cardiomyopathy (Geršl and Hrdina 1994, Šimůnek et al. 2004). Control and ketamine groups received saline $(2 \mathrm{ml} / \mathrm{kg}$, once weekly, 10 weeks).

Blood for cardiac troponin $\mathrm{T}$ analysis was sampled weekly immediately after the Doppler measurements. The heart rate was determined from ECG. Body weight gain at the end of the study was determined. At the end of the experiment (i.e. 4-5 days after the last administration), invasive hemodynamic measurements were performed. The animals were killed by pentobarbital overdose and their hearts were excised. The removed hearts underwent histological as well as biochemical examination.

\section{Echocardiography}

Since an echographic examination is not possible in conscious rabbits, the animals were anesthetized with injectable anesthetics. The ketamine group was anesthetized with ketamine alone $(50 \mathrm{mg} / \mathrm{kg}$, i.m.), while in the control and daunorubicin groups combined anesthesia was used (ketamine $50 \mathrm{mg} / \mathrm{kg}+$ xylazine $2 \mathrm{mg} / \mathrm{kg}$, i.m.). When the appropriate depth of anesthesia was reached (approx. $10 \mathrm{~min}$ ), the rabbits were placed on the table on the left lateral decubitus. The echocardiograms were obtained using a GE Vingmed CFM 800 apparatus (GE Vingmed Ultrasound, Norway) equipped with a $7.5 \mathrm{MHz}$ standard pediatric probe. The apical four-chamber view was obtained by means of the left parasternal approach. The HPRF (High Pulse Repetition Frequency) mode of pulse-wave Doppler imagining was used to study the LV-filling. The mitral inflow was recorded through a sample volume of $1.2 \mathrm{~mm}$ placed at the tips of the mitral valve leaflets. Evaluated parameters (peak filling rates of $\mathrm{E}$ and $\mathrm{A}$ wave, acceleration and deceleration times) were determined from 3-5 cardiac cycles, while at least three different Doppler recordings were obtained during each examination.

\section{Invasive hemodynamic measurements}

In pentobarbital anesthesia, the left carotid artery was prepared and a PE catheter (length $300 \mathrm{~mm}$, inner diameter $1.0 \mathrm{~mm})$, filled with heparinized $(10 \mathrm{IU} / \mathrm{ml})$ saline was introduced into the left heart ventricle. After a 15-min equilibration period, the measurement of the following parameters was performed: heart rate (HR), maximal rate of the pressure rise in the isovolumic phase of the systole (the maximum of the first derivative of LV pressure $-\mathrm{dP} / \mathrm{dt}_{\max }$ ) and the maximal rate of pressure decline in the isovolumic phase of diastole (the minimum of the first derivative of $\mathrm{LV}$ pressure $\left.-\mathrm{dP} / \mathrm{dt}_{\mathrm{min}}\right)$. Arterial blood pressure (BP) measurement was performed using another PE catheter inserted into the right femoral artery. ADI PowerLab 8SP apparatus (ADinstruments, Australia) with appropriate transducers and the software CHART for Windows 3.4.11 were used for pressure measurements, their differentiation and recording.

\section{Plasma levels of cardiac troponin $T$}

Concentrations of cardiac troponin $\mathrm{T}$ (cTnT) were determined in heparinized plasma samples using an Elecsys Troponin T STAT Immunoassay on an Elecsys 2010 immunoassay analyzer (Roche, Switzerland) according to the manufacturer's instructions. This thirdgeneration assay is based on electrochemiluminescence immunoassay technology (ECLIA) using two mouse monoclonal antibodies in a sandwich format (two step assay). These antibodies show no cross reactivity with skeletal TnT for concentrations up to $1000 \mathrm{mg} / \mathrm{ml}$ $(0.005 \%)$. The detection limit for the cTnT determination was $0.010 \mu \mathrm{g} / \mathrm{l}$ and values below this detection limit were considered to be zero. 


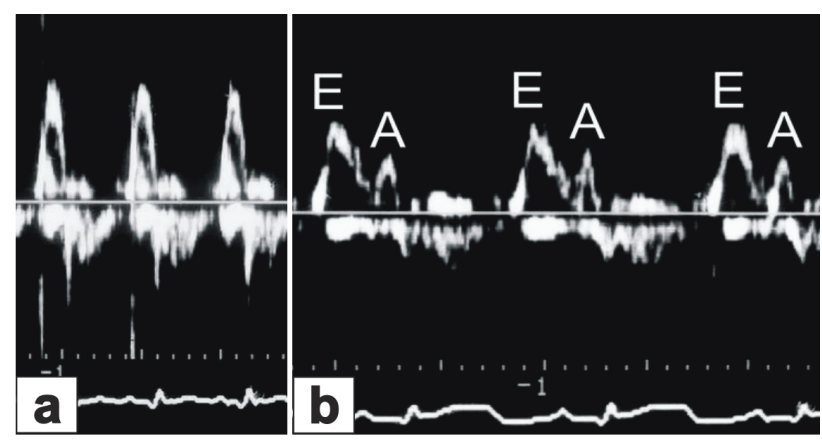

Fig. 1. Left ventricular transmitral inflow in rabbits anesthetized with a) ketamine $50 \mathrm{mg} / \mathrm{kg}$ or b) a combination of ketamine $50 \mathrm{mg} / \mathrm{kg}$ and xylazine $2 \mathrm{mg} / \mathrm{kg}$. " $E$ " - early (passive) and " $\mathrm{A}$ " - later (active) component of the left ventricular filling.

\section{Biochemical analysis of $L V$ samples}

Samples taken from the identical parts of the LV of the excised hearts were dried and after cooling period they were weighed and digested by microwave digestion with nitric acid and hydrogen peroxide. The total calcium content in the prepared samples was measured photometrically using flame photometry (Eppendorf, Efox 5053, Germany). Results are expressed as $\mu \mathrm{g} / \mathrm{g}$ of dry tissue.

The collagenous proteins of the LV myocardium were determined as hydroxyproline concentration with an adjustment by factor 7.46 as previously described (Pelouch et al. 1995). Hydroxyproline concentration was measured as follows: homogenates of myocardial tissue $(6.3 \%)$ were hydrolyzed with an equal volume of $4.2 \mathrm{~mol} / 1 \mathrm{NaOH}$ at $120{ }^{\circ} \mathrm{C}$ for $20 \mathrm{~min}$. Oxidation of the hydrolyzate $(0.1 \mathrm{ml})$ was started with the addition of chloramine-T reagent $(0.9 \mathrm{ml})$ at $25^{\circ} \mathrm{C}$ and was stopped after $50 \mathrm{~min}$ by adding Ehrlich's aldehyde reagent $(1.0 \mathrm{ml})$. After incubation of samples at $65^{\circ} \mathrm{C}$ for $20 \mathrm{~min}$ the absorbance of developed chromophore was read at $550 \mathrm{~nm}$.

\section{Histological examination}

After macroscopic examination, the heart was dissected and the tissue blocks of the transversely sectioned left and right cardiac ventricles and left atrium (incl. auricle) were taken for histological examination. The material was fixed by immersion in $4 \%$ formaldehyde for 5-7 days. Paraffin sections ( $6 \mu \mathrm{m}$ thick) were stained with hematoxylin-eosin and Masson's blue trichrome. Photomicrographs were made with a Lucia G software version 4.51 (Laboratory Imaging, Prague, Czech Republic). A six-point scale (Score 0 to 5) for the semiquantitative evaluation of histopathological changes
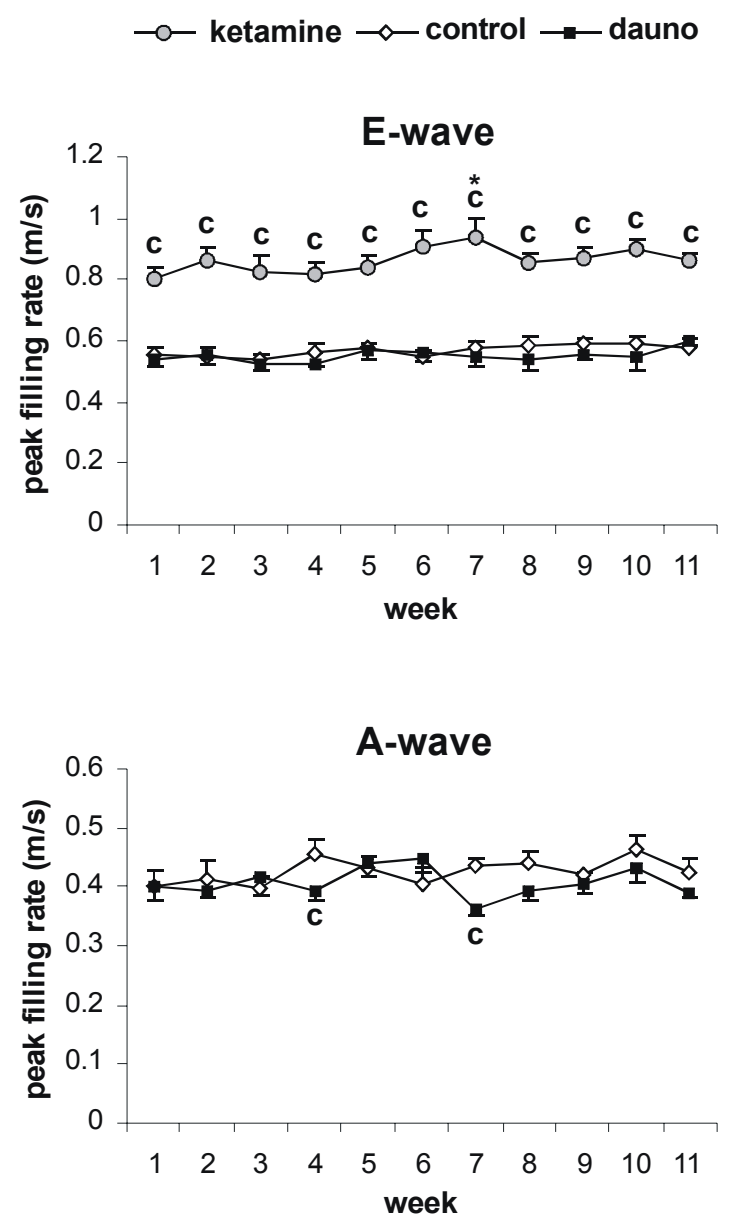

\section{E/A}

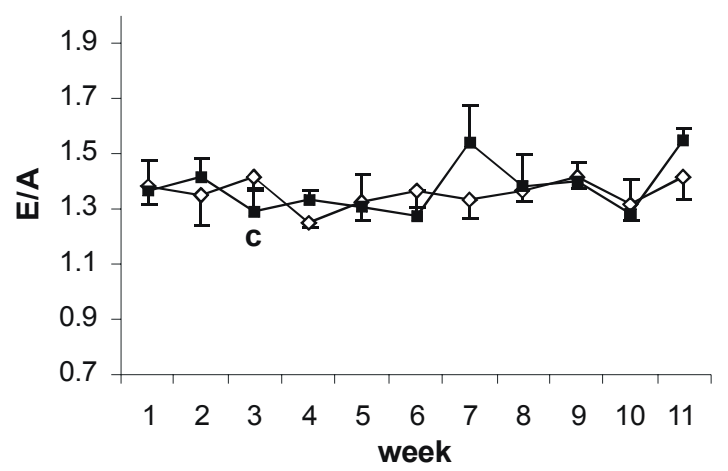

Fig. 2. Peak filling rates of the passive and active components of the left ventricular filling and their ratio during the experiment. " $E$ - wave" - early, passive component, "A - wave" - later, active component, and E/A - ratio of both peak filling rates. Statistical significance - "*" in comparison with the initial values within each group (paired t-test, $\mathrm{p}<0.05$ ) and " $\mathrm{c}$ " with the control group (ANOVA, $\mathrm{p}<0.05$ ).

in the myocardium was used as previously described (Šimůnek et al. 2004).

\section{Statistical analysis}

All results are expressed as mean \pm S.E.M. The 
Table 1. Heart rate and blood pressure at the end of the study

\begin{tabular}{lll}
\hline & HR (bpm) & BP (mm Hg) \\
\hline ketamine & $298 \pm 8$ & $96 \pm 6$ \\
control & $206 \pm 14^{+}$ & $75 \pm 8^{+}$ \\
daunorubicin & $178 \pm 23$ & $51 \pm 2^{\#}$ \\
\hline
\end{tabular}

$\mathrm{HR}=$ heart rate, $\mathrm{BP}=$ mean arterial blood pressure. Statistical significance (ANOVA, $\mathrm{p}<0.05$ ) in comparison with the control group "\#" and the ketamine group "+".

statistical software SigmaStat for Windows 3.0 (Jandel, Germany) was used in this study. Significances of the differences were estimated using the one-way ANOVA unpaired test (comparison between groups) or the Paired t-test (comparison with the initial value within one group). The data without a normal distribution were evaluated using the nonparametric tests: Kruskal-Wallis ANOVA on Ranks and Wilcoxon Signed Rank Test.

\section{Results}

\section{General toxicity}

One premature death was observed in the daunorubicin group (in the 7 th week). All animals in the control and ketamine groups survived until the end of the experiment. With respect to the initial body weights (control group $4.04 \pm 0.14 \mathrm{~kg}$, daunorubicin group $3.81 \pm$ $0.11 \mathrm{~kg}$, ketamine group $4.04 \pm 0.24 \mathrm{~kg}$ ), a significant increase of this parameter was observed at the end of the study in the ketamine $(111.5 \pm 2.6 \%, \mathrm{p}<0.05)$ and control $(117.2 \pm 2.1 \%, \mathrm{p}<0.05)$ groups, while in the daunorubicin group it remained unchanged $(99.0 \pm 7.3 \%$, n.s.). The final body weights in the daunorubicin group were also statistically lower than those determined in the control group $(\mathrm{p}<0.05)$.

\section{LV-filling pattern assessed by echocardiography}

The parameters of transmitral inflow were evaluated at weekly intervals, for 10 weeks, in two groups of rabbits (daunorubicin and control) anesthetized with the combined ketamine + xylazine regimen as well as in the ketamine group, where ketamine was employed as the only anesthesia. The results are summarized in Figure 2 (E-wave, A-wave, E/A) and Figure 3 (acceleration time, deceleration time). No significant changes in any parameter were observed in the control group. Surprisingly, no significant trend in any parameter could also be recognized in the daunorubicin group,
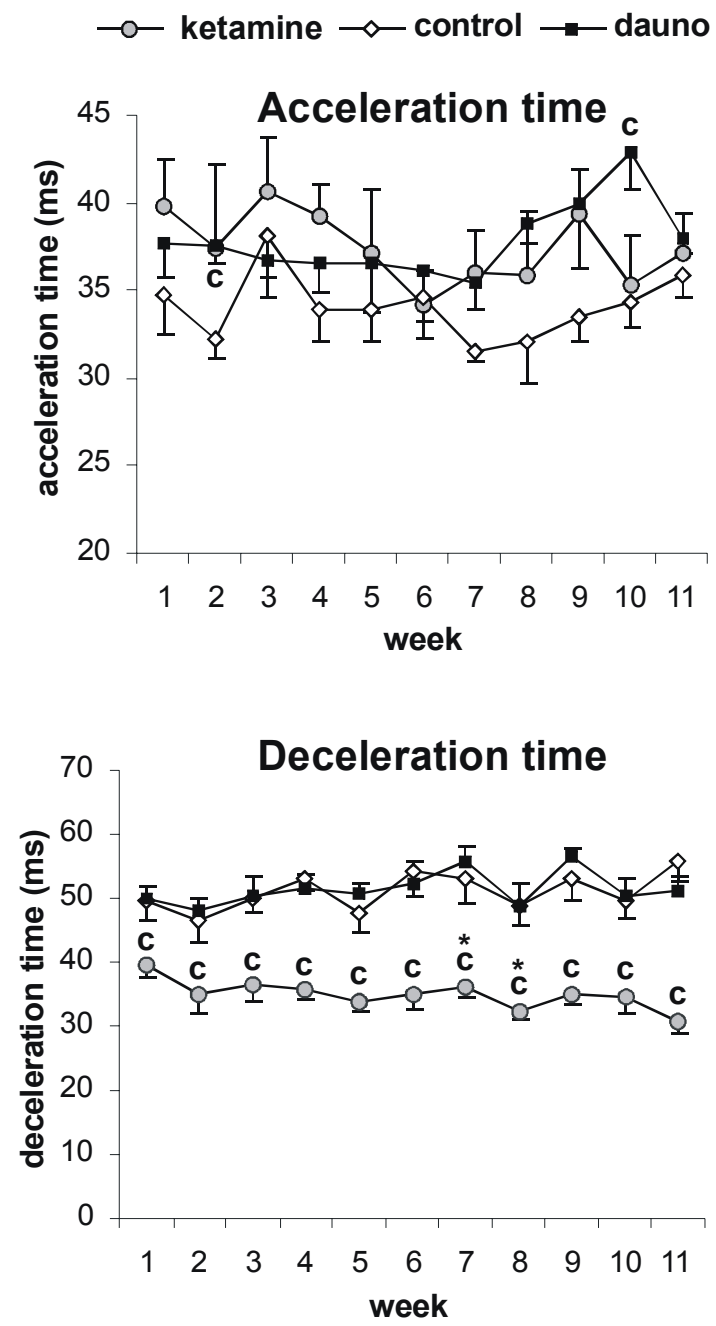

Fig. 3. Acceleration and deceleration times during the experiment. Statistical significance $-*$ in comparison with the initial values within each group (paired t-test, $p<0.05$ ) and "c" with the control group (ANOVA, $p<0.05$ ).

either in a comparison with the beginning of the experiment or in a comparison with the control group. Only few significant (but inconsistent) changes were observed in the daunorubicin group in comparison with the control group and no evident tendency could be distinguished. Unlike in the control and daunorubicin groups, where typical biphasic filling was observed (Fig. 1B), only a single high peak was observed in ketamine group (Fig. 1A), despite a maximal horizontal sweep setting. Therefore, it was only possible to determine the maximal peak-filling rate (E) and its acceleration and deceleration times. In comparison with both other groups, markedly different values were obtained in these parameters during the whole experiment, while only few other significant changes were noted (elevation of the maximal peak filling rate in the 7 th week and a moderate decrease in deceleration time in the 7 th and 8 th weeks). 


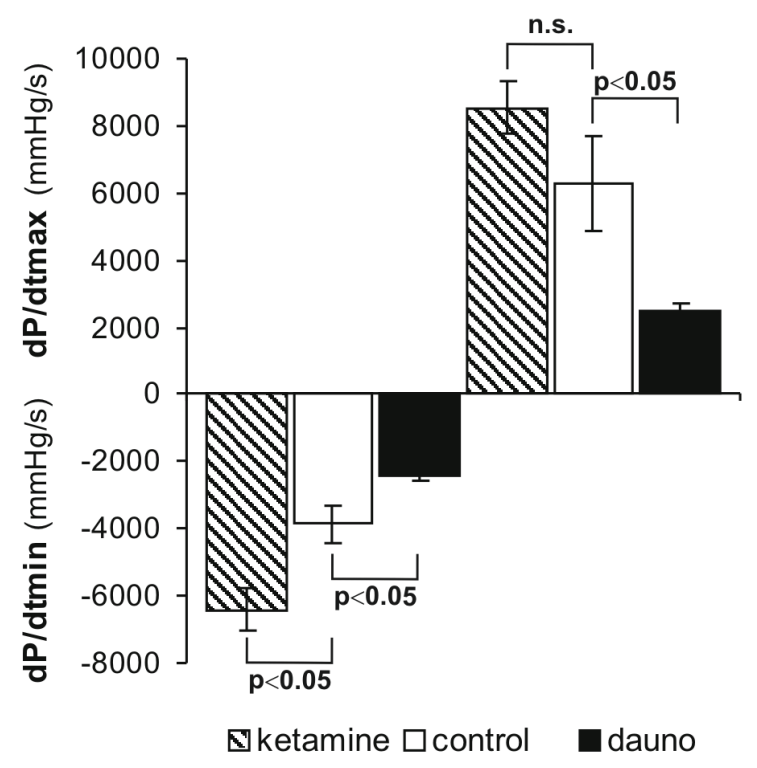

Fig. 4. Maximal rate of pressure decline in the isovolumic phase of diastole ( $\left.\mathrm{dP} / \mathrm{dt}_{\min }\right)$ and maximal rate of the pressure rise in the isovolumic phase of the systole $\left(\mathrm{dP}_{\mathrm{d}} / \mathrm{dt}_{\max }\right)$ determined invasively at the end of the study. Statistical significance (ANOVA, $p<0.05$ ), "n.s." - not significant.

\section{Invasive hemodynamic measurements}

At the end of the study, invasive hemodynamic measurements were performed. The parameters of the LV-relaxation $\left(\mathrm{dP} / \mathrm{dt}_{\min }\right)$ and contractility $\left(\mathrm{dP} / \mathrm{dt}_{\max }\right)$ are shown in Figure 4. A significantly lower $\mathrm{dP} / \mathrm{dt}_{\min }$ was determined in the daunorubicin group in comparison with the control group. However, an even more prominent difference in $\mathrm{dP} / \mathrm{dt}_{\min }$ was apparent between the control and ketamine groups, which suggest a significant impact of xylazine on this parameter. Furthermore, Figure 4 clearly demonstrates the significantly lower LV contractility $\left(\mathrm{dP} / \mathrm{dt}_{\max }\right)$ in the daunorubicin group as compared to the control group. Other hemodynamic parameters are summarized in Table 1. Although the mean heart rate was rather lower in the daunorubicin than in the control group, this did not reach statistical significance, whereas the difference in blood pressure was more prominent and significant. Furthermore, both the latter parameters were significantly lower in the control group (combined anesthesia) than in the ketamine group, which again points out the profound hemodynamic effect of xylazine.

\section{Plasma levels of cardiac troponin $T$}

Plasma cTnT levels in both the control and the ketamine groups were almost completely below the detection limit (i.e. $<0.010 \mu \mathrm{g} / \mathrm{l}$ ). Only a slight elevation above this limit was seen in a few rare cases. In contrast,

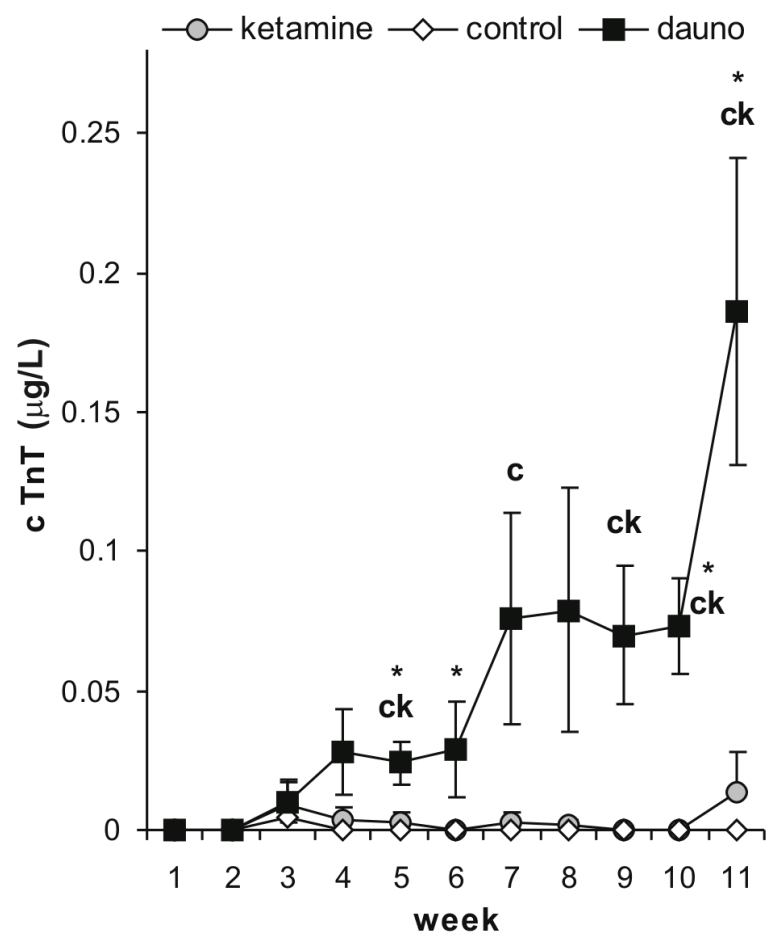

Fig. 5. Cardiac troponin $T$ plasma concentrations in the timecourse of the study. Statistical significance $-*$ in comparison with the initial values within each group (paired t-test, $p<0.05$ ) and " $\mathrm{c}$ ", " $\mathrm{k}$ " with the control group and ketamine group (ANOVA, $\mathrm{p}<0.05)$, respectively.

a marked progressive rise of cTnT levels was observed in the daunorubicin group commencing with the third to fourth week and reached statistical significance in the $5^{\text {th }}$ week (Fig. 5).

\section{Biochemical analysis of LV samples}

The myocardial content of total calcium in the LV samples was determined to be $10.25 \pm 1.36,10.60 \pm$ 0.67 and $15.79 \pm 2.05 \mu \mathrm{g} / \mathrm{g}$ of dry tissue for ketamine, control, and daunorubicin groups, respectively. While very similar values of total myocardial calcium were observed in the ketamine and control groups, a significant elevation of total calcium concentration was found in the daunorubicin group.

The total amount of collagen (i.e. both soluble and insoluble) in the LV myocardium was significantly higher in the daunorubicin group $(19.74 \pm 0.79 \mathrm{mg} / \mathrm{g}$ wet weight) than in the control and ketamine groups (14.43 \pm 0.37 and $12.95 \pm 1.4 \mathrm{mg} / \mathrm{g}$ wet weight, respectively).

\section{Histological examination}

In the LV myocardium obtained at the end of experiment from the ketamine and control groups (Figs 6A and 6B), only weak signs of myocardial changes 

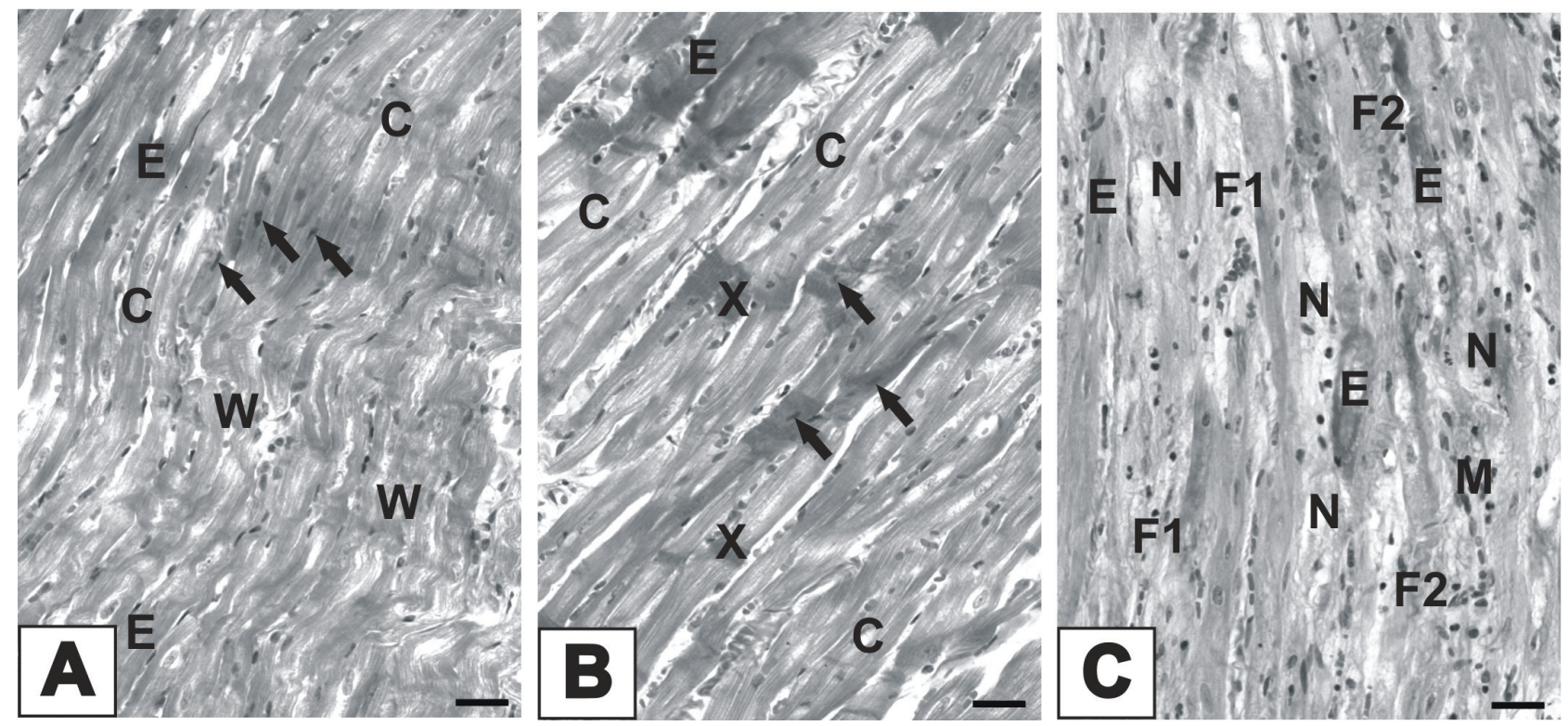

Fig. 6. Histological examination of the left ventricular myocardium. In both saline-receiving groups: ketamine (Fig A) and control (Fig $B$ ), increased eosinophilia of cytoplasm (E - homogenously eosinophilic cells, $X$ - eosinophilic strips in the cytoplasm of myocytes), woven myocytes (W) and some scattered pyknotic nuclei (arrows) are the only present changes (score 1). C - normal cardiomyocytes. In a sharp contrast, repeated administration of daunorubicin (Fig C) causes a massive injury of the myocardium (score 4). The number of intensely eosinophilic cells $(E)$ decreases whereas the foci of necrotic $(N)$ cardiomyocytes, followed by a conspicuous macrophagic infiltrate $(\mathrm{M})$, markedly increase in size and number. Healing process, i.e. the progressive interstitial fibrosis subsequently develops in this group. At first, the granulation tissue appears that mature to fibrotic tissue (marked by bundles of collagen fibers - F1). Finally, fibrotic scars of different size may also develop (F2). Masson's blue trichrome. Bar $30 \mu \mathrm{m}$.

were detected. Several scattered myocytes appeared to have increased eosinophilia of the cytoplasm, disintegration of myofibrils or pyknotic nuclei (Score 1). These changes were also observed in other parts of the heart wall without apparent local differences. On the contrary, a massive injury with the foci of necrotic cardiomyocytes, followed by a conspicuous macrophagic infiltrate (Score 3), and signs of progressive interstitial fibrosis (Score 4) were observed in the LV myocardium of all animals treated with daunorubicin (Fig. 6C). The most intensive morphological changes (particularly with respect to fibrosis) were observed in the LV free wall. Similar findings with somewhat lower incidence were also witnessed in the cardiac septum. The right ventricle wall was distinctly less damaged in this way. In the left atrium wall, the foci of scattered necrotic cardiomyocytes prevailed but no granular or fibrotic tissue was observed.

\section{Discussion}

Introduction of anthracycline antibiotics in the late 1960s represented one of the most important breakthroughs in modern oncology. Unfortunately, the risk of potentially fatal cardiomyopathy and heart failure remains a major complication with potentially severe consequences. The early detection of anthracycline cardiomyopathy is therefore crucial for patient's prognosis, since timely intervention (discontinuation of anthracycline treatment or indication of the cardioprotective agent - dexrazoxane) may allow preserving both myocardial integrity and function.

In our previous experiments, we have demonstrated that repeated 10-week daunorubicin administration ( $3 \mathrm{mg} / \mathrm{kg}$ weekly) is able to induce marked cardiomyopathy and impairment of systolic function in rabbits. However, the decline in the LV ejection fraction was significant only by the end of the 10-week experiment (Šimůnek et al. 2004). These findings correspond with rather lower sensitivity of the echographically-estimated ejection fraction (Shan et al. 1996). Therefore, the present study was designed to systematically investigate and compare the feasibility and utility of two independent approaches (echographically examined LV filling pattern and plasma levels of troponin $\mathrm{T}$ ) for early determination of anthracyclineinduced cardiotoxicity in rabbits. In this study, we show that relatively high heart rate (though physiological in this species) makes Doppler evaluation of the LV-filling troublesome. As we also attempted to perform the Doppler measurements using other anesthetics (e.g. a benzodiazepine midazolam) instead of ketamine without any improvement, incorrect anesthesia cannot be blamed 
from this complication (unpublished results). In contrast, combinational anesthetic regimen containing xylazine improved significantly the quality of Doppler recordings of transmitral inflow and the typical biphasic pattern has been reached (Fig. 1B). This improved quality of the recordings was obtained only at the expense of profound changes in the heart rate as well as other key cardiovascular variables (Table 1). Interestingly, this combination of injectable anesthetics is quite frequently used in experimental research and it can be also found in numerous echocardiographic studies performed on rabbits, rats and mice (Rungwerth et al. 2004, Bull et al. 2003, Derumeaux et al. 2002, Chaves et al. 2001, Teraoka et al. 2000, Tokudome et al. 2000, Nagueh et al. 2000, Pennock et al. 1997, Hoit et al. 1995, Litwin et al. 1994, Young et al. 1990).

In this study, we followed for the first time the LV-filling pattern in animals treated with daunorubicin in a standard schedule used for the induction of anthracycline cardiomyopathy. Surprisingly, no significant consistent changes in any parameter evaluated (E, A, E/A, acceleration time, deceleration time) could be observed during the whole study. With few rare exceptions, these values were similar to those in the control group. These results are also comparable to those referred for control groups in the literature (Rungwerth et al. 2004, Nagueh et al. 2000). Despite of the negative findings of the echographic part of this study, the diastolic dysfunction was clearly proved by more sensitive invasive measurement performed at the end of the study when the $\mathrm{dP} / \mathrm{dt}_{\min }$ index (maximal rate of pressure decline in the isovolumic phase of diastole) was significantly reduced (Fig. 4). However, the invasiveness of this approach markedly complicates the practical employment of this method and therefore its potential repeated use in clinical setting is virtually unfeasible. The discrepancy between the non-invasive and invasive evaluation of the LV diastolic function in the present experiment is supposed to be likely related to the lower sensitivity and specificity of the Doppler measurement of the LV-filling together with the confounding effects of xylazine-containing anesthesia, which significantly altered the hemodynamic parameters.

Our previous findings (Šimůnek et al. 2004) as well as other indices from this study strongly support the validity of the results of invasive measurements pointing out the significant abnormality in the diastolic function. The impairment in lusitropic properties of LV is known to be dependent on both myocyte component (represented mainly by calcium handling abnormality) and nonmyocyte component (connective tissue proliferation creating the basis for myocardial fibrosis) (Katz 2001). In the present study, the biochemical analysis of LV samples obtained from daunorubicin-treated animals revealed both significant impairment of total myocardial calcium content and marked elevation of the amount of collagenous proteins, which was also documented histologically (Fig. 6). Other morphological findings well documented typical left ventricular myocardial injury induced by chronic anthracycline treatment and are in agreement with previous reports (Herman et al. 1985, Šimůnek 2004).

In contrast to numerous complications experienced with serial evaluations of the LV-filling pattern, the troponin $\mathrm{T}$ plasma level, which is easy to obtain, represents a very sensitive marker of daunorubicin-induced cardiotoxicity. These experiments were first to systematically study the elevations of troponin $\mathrm{T}$ in the plasma throughout the whole course of development of anthracycline cardiotoxicity. We have found detectable elevations above the detection limit already since the 3-4th week of treatment (i.e. at cumulative dose of daunorubicin $\approx 100-150 \mathrm{mg} / \mathrm{m}^{2}$ ), while the rise of this marker became significant (cumulative dose of daunorubicin $\approx 200 \mathrm{mg} / \mathrm{m}^{2}$ ) from the 5th week. The progressive increase in cTnT levels well corresponds with the successive nature of chronic anthracycline cardiotoxicity, where the cardiac risk depends on the cumulative dose (von Hoff et al. 1979). Our results thus suggest that - at least in our experimental conditions - troponin $\mathrm{T}$ is the earliest and very useful marker of cardiac toxicity induced by daunorubicin. Moreover, troponin $\mathrm{T}$ is a marker, that may be applicable in other laboratory animal species (e.g. mouse, rat) employed for the modeling of anthracycline cardiotoxicity and evaluation of potential cardioprotectants (Wallace et al. 2004, Adamcová et al. 2005 ) and it can also be used in clinical practice.

In conclusion, using the standard echocardiography equipment, Doppler evaluation of the LV-filling pattern in rabbits seems to be complicated within the physiological heart rate. Xylazine-containing anesthesia enables high quality evaluation of diastolic filling in this species, but this approach does not have a predictive value for the development of myocardial damage induced by daunorubicin. In contrast to the Doppler assessment of diastolic function, plasma concentrations of cardiac troponin $\mathrm{T}$ were shown to be a 
sensitive marker of early daunorubicin cardiotoxicity, which may be used in different animal species as well as in clinical practice. Therefore, $\mathrm{cTnT}$ deserves further experimental as well as clinical research as a biomarker of anthracycline-induced cardiotoxicity.

\section{Acknowledgements}

The authors would like to thank Mrs. L. Koželuhová for her skilful technical assistance during the whole study and Assoc Prof. B. Mánek for his kind review of English. This study was supported by the Research Project of the Czech Ministry of Education, Youth and Sports MSM0021620820.

\section{References}

ADAMCOVÁ M, GERŠL V, HRDINA R, MĚLKA M, MAZUROVÁ Y, VÁVROVÁ J, PALIČKA V, KOKSTEIN Z: Cardiac troponin $\mathrm{T}$ as a marker of myocardial damage caused by antineoplastic drugs in rabbits. $J$ Cancer Res Clin Oncol 125: 268-274, 1999.

ADAMCOVÁ M, ŠTĚRBA M, ŠIMŮNEK T, POTÁČOVÁ A, POPELOVÁ O, MAZUROVÁ Y, GERŠL V: Troponin as a marker of myocardiac damage in drug-induced cardiotoxicity. Expert Opin Drug Saf 4: 457-472, 2005.

ALEXANDER J, DAINIAK N, BERGER HJ, GOLDMAN L, JOHNSTONE D, REDUTO L, DUFFY T, SCHWARTZ P, GOTTSCHALK A, ZARET BL: Serial assessment of doxorubicin cardiotoxicity with quantitative radionuclide angiocardiography. $N$ Engl J Med 300: 278-83, 1979.

BOSSI G, LANZARINI L, LAUDISA ML, KLERSY C, RAISARO A, ARICO M: Echocardiographic evaluation of patients cured of childhood cancer: a single center study of 117 subjects who received anthracyclines. Med Pediatr Oncol 36: 593-600, 2001.

BU'LOCK FA, MOTT MG, OAKHILL A, MARTIN RP: Left ventricular diastolic filling patterns associated with progressive anthracycline-induced myocardial damage: a prospective study. Pediatr Cardiol 20: 252-263, 1999.

BULL DA, BAILEY SH, RENTZ JJ, ZEBRACK JS, LEE M, LITWIN SE, KIM SW: Effect of Terplex/VEGF-165 gene therapy on left ventricular function and structure following myocardial infarction. VEGF gene therapy for myocardial infarction. J Control Release 93: 175-181, 2003.

CARDINALE D, SANDRI MT, COLOMBO A, COLOMBO N, BOERI M, LAMANTIA G, CIVELLI M, PECCATORI F, MARTINELLI G, FIORENTINI C, CIPOLLA CM: Prognostic value of troponin I in cardiac risk stratification of cancer patients undergoing high-dose chemotherapy. Circulation 109: 2749-2754, 2004.

CHABNER BA, AMREIN PC, DRUKER B, MICHAELSON MD, MITSIADES CS, GROSS PE, RYAN DP, RAMACHANDRA S, RICHARDSON PG, SUPKO, WILSON WH: Antineoplastic Agents. In: Goodman \& Gillman's Pharmacological Basis of Therapeutics. BURTON LL, LAZO JS, PARKER KL (Eds), McGrawHill, New York, 2006, pp 1315-1404.

CHAVES AA, WEINSTEIN DM, BAUER JA: Non-invasive echocardiographic studies in mice: influence of anesthetic regimen. Life Sci 69: 213-222, 2001.

CLEMENTS IP, DAVIS BJ, WISEMAN GA: Systolic and diastolic cardiac dysfunction early after the initiation of doxorubicin therapy: significance of gender and concurrent mediastinal radiation. Nucl Med Commun 23: 521527, 2002.

DERUMEAUX G, MULDER P, RICHARD V, CHAGRAOUI A, NAFEH C, BAUER F, HENRY JP, THUILLEZ C: Tissue Doppler imaging differentiates physiological from pathological pressure-overload left ventricular hypertrophy in rats. Circulation 105: 1602-1608, 2002.

ELBL L, HRSTKOVÁ H, CHALOUPKA V: The late consequences of anthracycline treatment on left ventricular function after treatment for childhood cancer. Eur J Pediatr 162: 690-696, 2003.

ELBL L, HRSTKOVÁ H, TOMÁŠKOVÁ I, BLAŽEK B, MICHÁLEK J: Long-term serial echocardiographic examination of late anthracycline cardiotoxicity and its prevention by dexrazoxane in paediatric patients. Eur $J$ Pediatr 164: 678-684, 2005.

EWER MS, ALI MK, GIBBS HR, SWAFFORD J, GRAFF KL, CANGIR A, JAFFE N, THAPAR MK: Cardiac diastolic function in pediatric patients receiving doxorubicin. Acta Oncol 33: 645-649, 1994. 
GERŠL V, HRDINA R: Noninvasive polygraphic cardiac changes in daunorubicin-induced cardiomyopathy in rabbits. Sb Ved Pr Lek Fak Karlovy Univerzity Hradci Kralove 37: 49-55, 1994.

GHARIB MI, BURNETT AK: Chemotherapy-induced cardiotoxicity: current practice and prospects of prophylaxis. Eur J Heart Fail 4: 235-242, 2002.

HOIT BD, KHOURY SF, KRANIAS EG, BALL N, WALSH RA: In vivo echocardiographic detection of enhanced left ventricular function in gene-targeted mice with phospholamban deficiency. Circ Res 77: 632-637, 1995.

HERMAN EH, EL-HAGE AN, FERRANS VJ, ARDALAN B: Comparison of the severity of the chronic cardiotoxicity produced by doxorubicin in normotensive and hypertensive rats. Toxicol Appl Pharmacol 78: 202-214, 1985.

HERMAN EH, LIPSHULTZ SE, RIFAI N, ZHANG J, PAPOIAN T, YU ZX, TAKEDA K, FERRANS VJ: Use of cardiac troponin T levels as an indicator of doxorubicin-induced cardiotoxicity. Cancer Res 58: 195-197, 1998.

HORÁČEK JM, PUDIL R, TICHÝ M, JEBAVÝ L, STRAŠOVÁ A, PRAUS R, ŽÁK P, MALÝ J: The use of biochemical markers in cardiotoxicity monitoring in patients treated for leukemia. Neoplasma 52: 430-434, 2005.

HRDINA R, GERŠL V, KLIMTOVÁ I, ŠIMŮNEK T, MACHÁČKOVÁ J, ADAMCOVÁ M: Anthracycline-induced cardiotoxicity. Acta Medica (Hradec Kralove) 43: 75-82, 2000.

KATZ, AM: Physiology of the Heart. Lippincott Williams and Wilkins, Philadelphia, 2001.

KOH E, NAKAMURA T, TAKAHASHI H: Troponin-T and brain natriuretic peptide as predictors for adriamycininduced cardiomyopathy in rats. Circ J 68: 163-167, 2004.

LITWIN SE, KATZ SE, MORGAN JP, DOUGLAS PS: Serial echocardiographic assessment of left ventricular geometry and function after large myocardial infarction in the rat. Circulation 89: 345-354, 1994.

LIPSHULTZ SE, RIFAI N, SALLAN SE, LIPSITZ SR, DALTON V, SACKS DB, OTTLINGER ME: Predictive value of cardiac troponin $\mathrm{T}$ in pediatric patients at risk for myocardial injury. Circulation 96: 2641-2648, 1997.

LIPSHULTZ SE, RIFAI N, DALTON VM, LEVY DE, SILVERMAN LB, LIPSITZ SR, COLAN SD, ASSELIN BL, BARR RD, CLAVELL LA, HURWITZ CA, MOGHRABI A, SAMSON Y, SCHORIN MA, GELBER RD, SALLAN SE: The effect of dexrazoxane on myocardial injury in doxorubicin-treated children with acute lymphoblastic leukemia. N Engl J Med 351: 145-153, 2004.

MARCHANDISE B, SCHROEDER E, BOSLY A, DOYEN C, WEYNANTS P, KREMER R, POULEUR H: Early detection of doxorubicin cardiotoxicity: interest of Doppler echocardiographic analysis of left ventricular filling dynamics. Am Heart J 118: 92-98, 1989.

MINOTTI G, MENNA P, SALVATORELli E, CAIRO G, GIANNI L: Anthracyclines: molecular advances and pharmacologic developments in antitumor activity and cardiotoxicity. Pharmacol Rev 56: 185-229, 2004.

NAGUEH SF, KOPELEN HA, LIM DS, ZOGHBI WA, QUINONES MA, ROBERTS R, MARIAN AJ: Tissue Doppler imaging consistently detects myocardial contraction and relaxation abnormalities, irrespective of cardiac hypertrophy, in a transgenic rabbit model of human hypertrophic cardiomyopathy. Circulation 102: 1346-1350, 2000.

NAKAMAE H, TSUMURA K, AKAHORI M, TERADA Y, YAMANE T, HAYASHI T, SAITO I, KANEKO M, OKAMOTO N, ICHIHARA Y, OHTA K, HINO M: QT dispersion correlates with systolic rather than diastolic parameters in patients receiving anthracycline treatment. Intern Med 43: 379-387, 2004.

NOUSIAINEN T, VANNINEN E, JANTUNEN E, PUUSTINEN J, REMES J, RANTALA A, VUOLTEENAHO O, HARTIKAINEN J: Natriuretic peptides during the development of doxorubicin-induced left ventricular diastolic dysfunction. J Intern Med 251: 228-234, 2002.

PELOUCH V, MILEROVÁ M, OŠŤÁDAL B, HUČÍN B, ŠAMÁNEK M: Differences between atrial and ventricular protein profiling in children with congenital heart disease. Mol Cell Biochem 147: 43-49, 1995.

PENNOCK GD, YUN DD, AGARWAL PG, SPOONER PH, GOLDMAN S: Echocardiographic changes after myocardial infarction in a model of left ventricular diastolic dysfunction. Am J Physiol 273: H2018-H2029, 1997. 
PETRICOIN EF, RAJAPASKE V, HERMAN EH, AREKANI AM, ROSS S, JOHANN D, KNAPTON A, ZHANG J, HITT BA, CONRADS TP, VEENSTRA TD, LIOTTA LA, SISTARE FD: Toxicoproteomics: serum proteomic pattern diagnostics for early detection of drug induced cardiac toxicities and cardioprotection. Toxicol Pathol 32: 122-130, 2004.

RUNGWERTH K, SCHINDLER U, GERL M, SCHAFER S, LICHER T, BUSCH AE, RUETTEN H: Inhibition of $\mathrm{Na}^{+}-\mathrm{H}^{+}$exchange by cariporide reduces inflammation and heart failure in rabbits with myocardial infarction. Br J Pharmacol 142: 1147-1154, 2004.

SHAN K, LINCOFF AM, YOUNG JB: Anthracycline-induced cardiotoxicity. Ann Intern Med 125: 47-58, 1996.

ŠIMŮNEK T, KLIMTOVÁ I, KAPLANOVÁ J, MAZUROVÁ Y, ADAMCOVÁ M, ŠTĚRBA M, HRDINA R, GERŠL V: Rabbit model for in vivo study of anthracycline-induced heart failure and for the evaluation of protective agents. Eur J Heart Fail 6: 377-387, 2004.

SPECCHIA G, BUQUICCHIO C, PANSINI N, DI SERIO F, LISO V, PASTORE D, GRECO G, CIUFFREDA L, MESTICE A, LISO A: Monitoring of cardiac function on the basis of serum troponin I levels in patients with acute leukemia treated with anthracyclines. J Lab Clin Med 145: 212-220, 2005.

SUTER TM, MEIER B: Detection of anthracycline-induced cardiotoxicity: is there light at the end of the tunnel? Ann Oncol 13: 647-649, 2002.

TERAOKA K, HIRANO M, YAMAGUCHI K, YAMASHINA A: Progressive cardiac dysfunction in adriamycininduced cardiomyopathy rats. Eur J Heart Fail 2: 373-378, 2000.

TJEERDSMA G, MEINARDI MT, VAN DER GRAAF WT, VAN DEN BERG MP, MULDER NH, CRIJNS HJ, DE VRIES EG, VAN VELDHUISEN DJ: Early detection of anthracycline induced cardiotoxicity in asymptomatic patients with normal left ventricular systolic function: autonomic versus echocardiographic variables. Heart 81: 419-423, 1999.

TOKUDOME T, MIZUSHIGE K, NOMA T, MANABE K, MURAKAMI K, TSUJI T, NOZAKI S, TOMOHIRO A, MATSUO $\mathrm{H}$ : Prevention of doxorubicin (adriamycin)-induced cardiomyopathy by simultaneous administration of angiotensin-converting enzyme inhibitor assessed by acoustic densitometry. J Cardiovasc Pharmacol 36: 361-368, 2000.

VON HOFF DD, LAYARD MW, BASA P, DAVIS HL JR, VON HOFF AL, ROZENCWEIG M, MUGGIA FM: Risk factors for doxorubicin-induced congestive heart failure. Ann Intern Med 91: 710-717, 1979.

WALLACE KB, HAUSNER E, HERMAN E, HOLT GD, MACGREGOR JT, METZ AL, MURPHY E, ROSENBLUM IY, SISTARE FD, YORK MJ: Serum troponins as biomarkers of drug-induced cardiac toxicity. Toxicol Pathol 32: 106-121, 2004.

YEE GC: Oncologic disorders. In: Pharmacotherapy: A Pathophysiologic Approach. DIPIRO JT, TALBERT RL, YEE GC, MATZKE GR, WELLS BG, POSEY MI (eds), McGraw-Hill, New York, 2005, pp. 2279-2328.

YOUNG MS, MAGID NM, WALLERSON DC, GODWEIT RS, DEVEREUX RB, CARTER JN, IM J, HALL MA, BORER JS: Echocardiographic left ventricular mass measurement in small animals: anatomic validation in normal and aortic regurgitant rabbits. Am J Noninvasive Cardiol 4: 145-153, 1990.

\section{Corresponding author}

Martin Štěrba, Charles University in Prague, Faculty of Medicine in Hradec Králové, Department of Pharmacology, Šimkova 870, 50038 Hradec Králové 1, Czech Republic. Fax: +420 495518 509. E-mail: sterbam@lfhk.cuni.cz 